\title{
Application of the Jaya algorithm to solve the optimal reliability allocation for reduction oxygen supply system of a spacecraft
}

\author{
Saad Abbas Abed ${ }^{1}$, Mohammad Aljanabi ${ }^{2}$, Noor Hayder Abdul Ameer ${ }^{3}$, Mohd Arfian Ismail ${ }^{4}$, \\ Shahreen Kasim ${ }^{5}$, Rohayanti Hassan ${ }^{6}$, Tole Sutikno ${ }^{7}$ \\ 1,2 Department of computer, College of Education, AL-Iraqia University, Iraq \\ ${ }^{3}$ Department of Computer Sciences, University of Technology, Iraq \\ ${ }^{4}$ Faculty of Computing, College of Computing and Applied Sciences, Universiti Malaysia Pahang, Malaysia \\ ${ }^{5}$ Faculty of Computing Science and Information Technology, Universiti Tun Hussein Onn, Malaysia \\ ${ }^{6}$ School of Computing, Faculty of Engineering, Universiti Teknologi Malaysia, Malaysia \\ ${ }^{7}$ Department of Electrical Engineering, Universitas Ahmad Dahlan, Yogyakarta, Indonesia
}

\section{Article Info \\ Article history: \\ Received Dec 23, 2020 \\ Revised Sep 5, 2021 \\ Accepted Sep 11, 2021}

\section{Keywords:}

Jaya algorithm

Optimal reliability allocation

Reduction oxygen

Reliability network

Reliability optimization

Spacecraft

\begin{abstract}
In this paper the reliability of reduction oxygen supply system (ROSS) of a spacecraft which was calculated as a complex system using minimal cut method. The reliability of each component of system was calculated as well as the reliability importance of the system. The cost of each component of the system was possible approaches of the allocation values of reliability based the minimization of the overall cost in this system. The advantage of this algorithm can be used to allocate the optimization of reliability for simple or complex system. This optimization is achieved using the Jaya algorithm. The proposed technique is based on the notion that a conclusion reached on a particular problem should pass near the best results and avoid the worst outcomes. The original findings of this paper are: i) the system used in this paper is a spacecraft's reduced oxygen supply system with the logarithmic cost function; and ii) the results obtained were by using the Jaya algorithm to solve specific system reliability optimization problems.
\end{abstract}

This is an open access article under the CC BY-SA license.

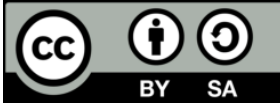

\section{Corresponding Author:}

Mohammad Aljanabi

Department of Computer, College of Education, AL-Iraqia University

Hayba Katoon, Street 22, Avenue 308, Adhamyh, Baghdad, Iraq

Email: mohammad.cs88@gmail.com

\section{INTRODUCTION}

One of the first researchers to take up the reduction oxygen supply system (ROSS) study of a spacecraft system for the first time by Aggarwal [1], and due to the importance of the topic in terms of engineering and science, light was re-shed by several researchers such as Hassan et al. [2]-[9] where the researchers discussed the reliability of this system and the study of mean time to failure (MTTF) using the engineering properties of many reliability limits. Also Abed et al. [10] discussed the issue of optimizing the reliability of this system has solved by using a genetic algorithm.

A ROSS of a spacecraft consists of a group of subsystems that are interconnected in a specific way that requires the designer to either maximize the reliability of the system while reducing the total cost or reduce the costs to the lowest possible level with appropriate reliability so that the system works in a suitable performance and in a specific period of time due to the current budget only. Many researchers have addressed the problem of optimizing the reliability of this in electrical or mechanical and electromagnetic systems and 
in many fields [11]-[19]. The complexity or reliability appropriate for the system's continuous operation for a specific period of time and there are other factors that the specialist considers appropriate [20]-[24].

This paper studies the problem of optimal allocating reliability as a mathematical problem even though problems roots belong to network. This paper deals with the problem of optimization of the device ROSS [25]-[28]. The system consists of subsystems or components where the reliability requirements between the subsystems or components are determined based on the importance of reliability or the location of the component in the system. The model for a component's reliability allocation is based on the cost of increasing reliability that's own. The costliest elements will be (the cost expressing by weight, cost, size, or any other amount) increases in reliability. By using these algorithms, it is possible to assign reliability to some or all of the components of any system, whether that system is complex or not [29]-[33]. Parameters are possible to be change the of the proposed cost function according to business requirements or the actual need for the system to function well, which will have engineers examine allocation scenarios for reliability in all respects before making decisions. The logarithmic cost function is increasing and convex. Also, the results obtained after solving the optimization problem using the Jaya algorithm [34]-[68] contributed to improving the optimization of the system reliability with appropriate costs [33], [69]-[80].

\section{RESEARCH METHOD}

\subsection{Optimization for ROSS of a spacecraft}

Consider a ROSS of a spacecraft consisting of elements connected reliability [15], [81]-[84], the following notes are used:

- $\quad 0 \leq R_{i} \leq 1$ is the element reliability $\mathrm{i}$

- $C_{i}\left(Q_{i}\right)$ is the cost of the element $\mathrm{i}$

- $C\left(Q_{1}, \ldots, Q_{n}\right)=\sum_{i=1}^{n} a_{i} C_{i}\left(Q_{i}\right)$ the system's total cost, where $a_{i}>0$

- $Q_{i}$ : is unreliability

- $Q_{s}$ : is the unreliability of the system

- $Q_{G}$ : is the unreliability goal of the system

The main goal of the problem is to allocate reliability to some or all components of the system to reduce costs to the least possible. The problem $\mathrm{P}$ will be formulated as the objective function (cost function) and the constraints as the optimization problem in nonlinear programming as (1):

$$
\begin{aligned}
& P \text { : Find Minimize } C\left(Q_{1}, \ldots, Q_{n}\right)=\sum_{i=1}^{n} a_{i} C_{i}\left(Q_{i}\right), a_{i}>0 \\
& \text { subject to }(1-Q s) \geq(1-Q G) 0 \leq Q_{i} \leq 1, i=1,2, \ldots, n
\end{aligned}
$$

where $R_{i}+Q_{i}=1$, assuming $C_{i}\left(Q_{i}\right)$ the cost function be positive and differentiable [21]: $\left[\Rightarrow \frac{d C_{i}}{d Q_{i}} \geq 0\right]$. The cost convexity of Euclidean function is to minimize the cost function. This is the same as the derivative $\frac{d C_{i}}{d Q_{i}}$ is monotonically increasing, i,e., $\frac{d^{2} C_{i}}{d Q_{i}^{2}} \geq 0$. The purpose of the previous plan is to achieve an all-out framework cost base [4], subject to $R_{G}$, the lower system reliability limit.

\subsection{Model of logarithmic function}

Let $0<Q_{i}<1$ and $K_{i}$, constant, $i=1,2, \ldots, n$, the cost function has been proposed in a number of references. The most important of which are in the form formula give the following cost unreliability curve as (2).

$$
c_{i}=K_{i} \ln \left(\frac{1}{1-\left(1-Q_{i}\right)}\right), K_{i}>0
$$

Consequently, each $C_{i}\left(Q_{i}\right)$ it is a monotony increasing and convex function in. The cost of the entire $C\left(Q_{1}, \ldots, Q_{n}\right)=\sum_{i=1}^{n} a_{i} C_{i}\left(Q_{i}\right)$ has similar characteristics [3].

\subsection{Jaya algorithm}

Jaya algorithm can solve optimization problems and it is one of the methods used to solving linear and nonlinear problems (with constraint or unconstraint), and this algorithm has been applied in many of the most difficult optimization problems [29], [74]. An important difference between Jaya and the other algorithm in optimization is that parameters of Jaya does not require tuning (a process required in other algorithms to avoid unwanted convergence). Another difference is Jaya's efficiency in always choosing the best solution. Next is the steps of Jaya algorithm and Figure 1 shows in flowchart form. 
Step-1 : Set population size (p-size), unreliability, mutation unreliability (p-mute), maximum generation (max-gen) and bounds of the variables.

Step-2 : Initialize the unreliability of individual components $Q_{i}\left[Q_{i}\right.$ represents the component at i-th generation].

Step-3 : Evaluate each component's cost function $c_{i}\left(Q_{i}\right)$ consider the function of an objective as a cost function.

Step-4 : Find the component's lowest unreliability $Q_{i}$.

Step-5 : Go to Step-12 if the termination criterion is met, otherwise go to the next step.

Step-6 : Component selection $Q_{i}$ component iteration $\mathrm{j} Q_{j}$ iteration j, by tournament selection process of the earlier generation.

Step-7 : Change the unreliability $Q_{i}$ by operators of crossover, mutation and elitism.

Step-8 : Assess the cost function value of each $Q_{i}$.

Step-9 : Find each component's best reliability

Step-10 : Compare and better store the lowest unreliability of each $Q_{i}$ iteration component $\mathrm{j}$ and the unreliability of each component iteration j $Q_{j}$.

Step-11 : Print the best unreliability of each component (Which is the solution to the problem of optimization).

Step-12 : Calculate the Reliability of each component $R_{i}$ by the equation $R_{i}+Q_{i}=1$.

Step-13 : The end.

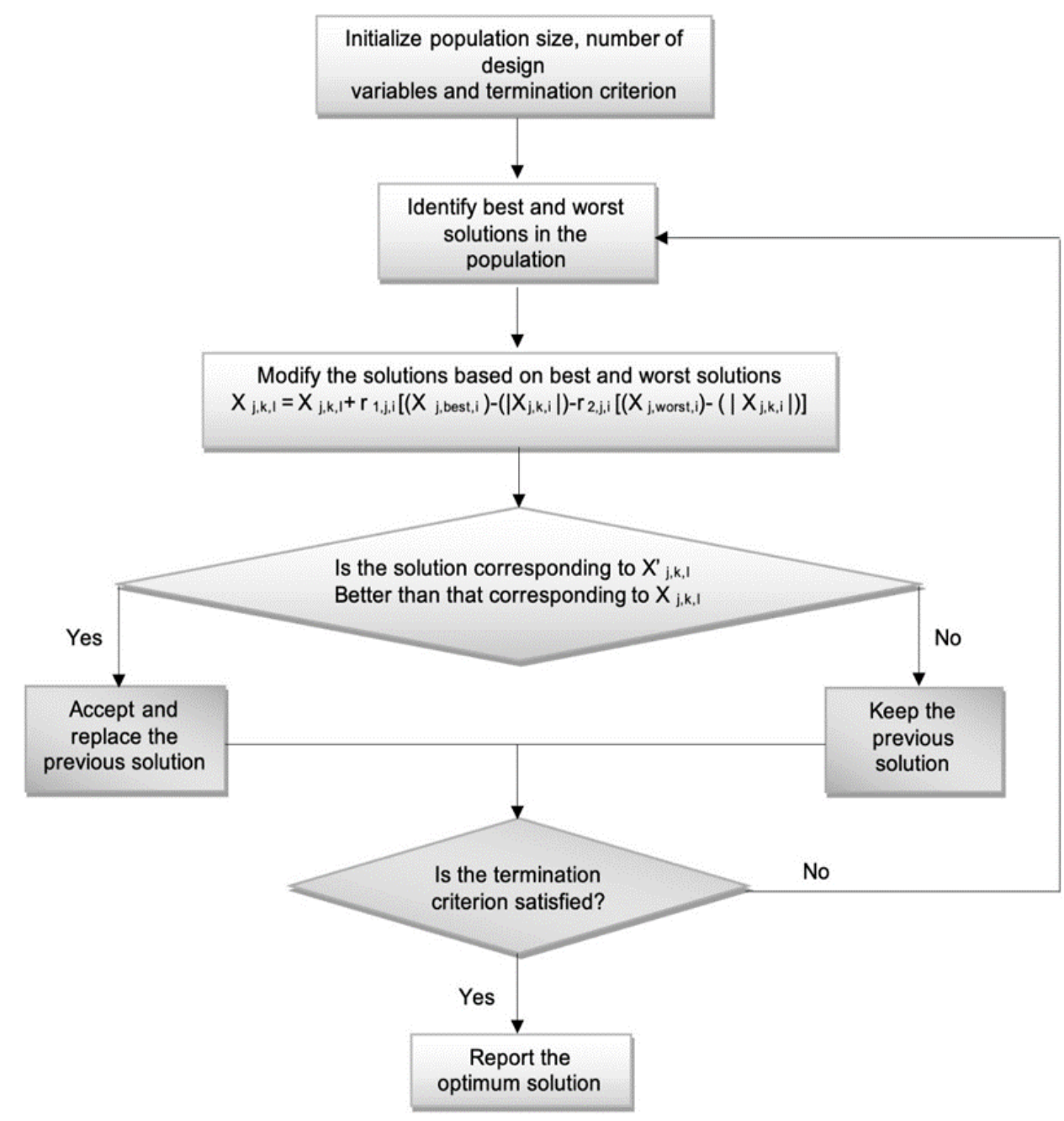

Figure 1. Flowchart of the Jaya algorithm 


\section{RESULTS AND DISCUSSIONS}

Let us have a ROSS system consisting of 11 components, which is as shown in Figure 2 and after reducing the number of components, the number of components became 7 as shown in Figure 3 , where (check valve, shut off valve, non-return automatic emergency valve) was connected in parallel in one component, so that the component number was (5) as well in the same way for the component number (6), has the same primary unreliability in all components that have at $0.2 \%$ at a specified time.

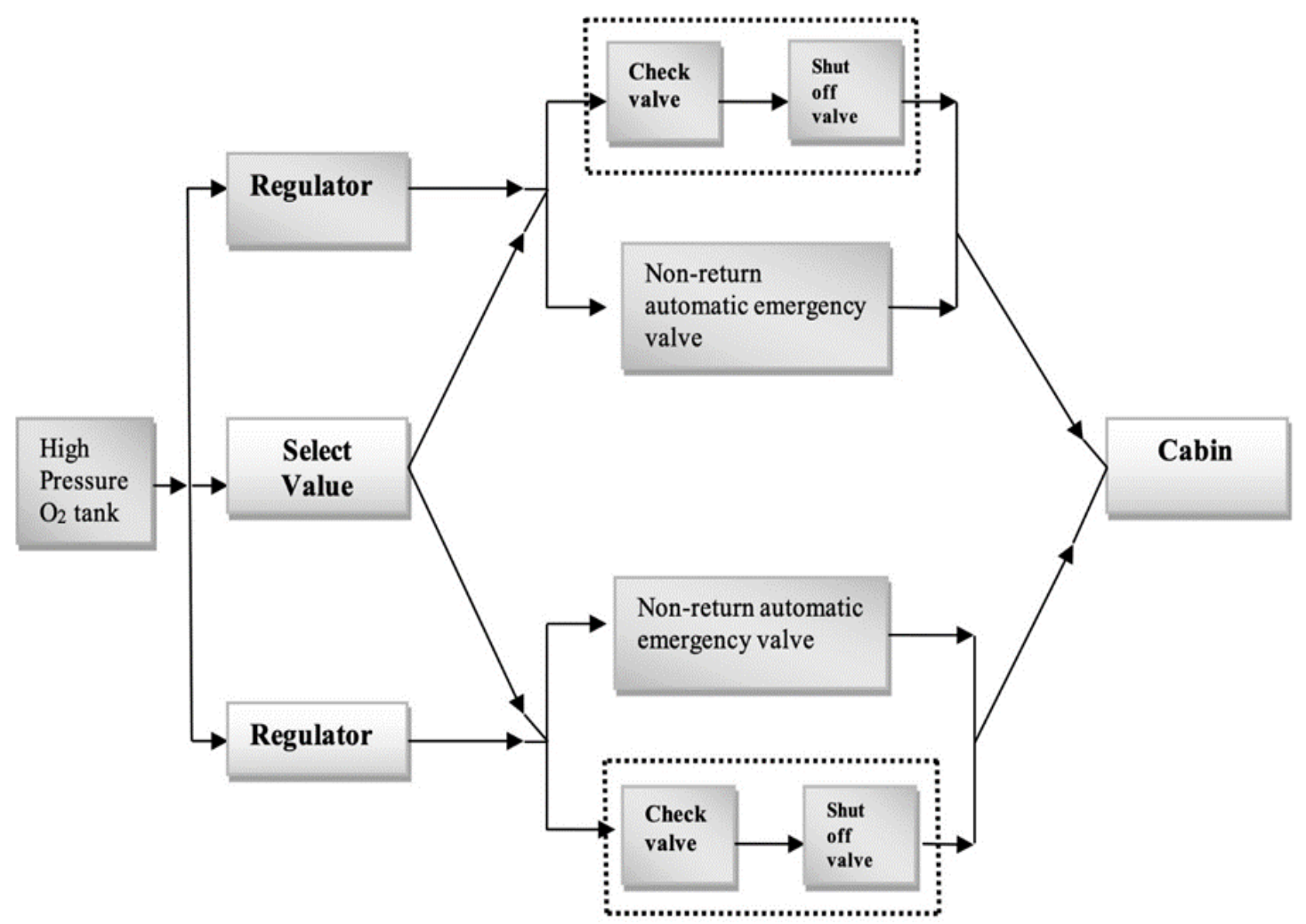

Figure 2. Oxygen supply system of a spacecraft

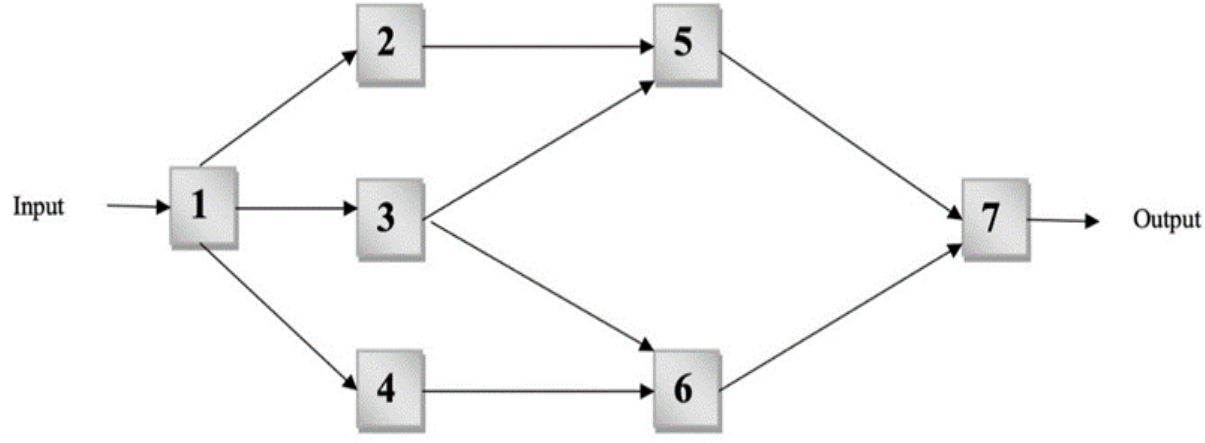

Figure 3. ROSS of a spacecraft after reducing

The system unreliability objective at a specified time is $0.1 \%$. The polynomial unreliability of the given system was calculated using the minimal cut method as (3). 


$$
\begin{aligned}
(1-Q s)= & \left(1-Q_{1}\right)\left(1-Q_{2}\right)\left(1-Q_{5}\right)\left(1-Q_{7}\right)+\left(1-Q_{1}\right)\left(1-Q_{3}\right)\left(1-Q_{5}\right)\left(1-Q_{7}\right) \\
& +\left(1-Q_{1}\right)\left(1-Q_{3}\right)\left(1-Q_{6}\right)\left(1-Q_{7}\right)+\left(1-Q_{1}\right)\left(1-Q_{4}\right)\left(1-Q_{6}\right)\left(1-Q_{7}\right) \\
& -\left(1-Q_{1}\right)\left(1-Q_{2}\right)\left(1-Q_{3}\right)\left(1-Q_{5}\right)\left(1-Q_{7}\right) \\
& -\left(1-Q_{1}\right)\left(1-Q_{3}\right)\left(1-Q_{4}\right)\left(1-Q_{6}\right)\left(1-Q_{7}\right) \\
& -\left(1-Q_{1}\right)-\left(1-Q_{1}\right)\left(1-Q_{3}\right)\left(1-Q_{5}\right)\left(1-Q_{6}\right)\left(1-Q_{7}\right) \\
& -\left(1-Q_{1}\right)\left(1-Q_{2}\right)\left(1-Q_{4}\right)\left(1-Q_{5}\right)\left(1-Q_{6}\right)\left(1-Q_{7}\right) \\
& +\left(1-Q_{1}\right)\left(1-Q_{2}\right)\left(1-Q_{3}\right)\left(1-Q_{4}\right)\left(1-Q_{5}\right)\left(1-Q_{6}\right)\left(1-Q_{7}\right)
\end{aligned}
$$

The final formulation of the optimization problem for allocation reliability becomes as given in (4).

$$
\text { Minimize } C\left(Q_{1}, \ldots, Q_{n}\right)=\sum_{i=1}^{n} K_{i} \ln \left(\frac{1}{1-\left(1-Q_{i}\right)}\right), K_{i}>0, i=1,2, \ldots, n
$$

Before solving the problem of assigning reliability to each part of the system, an initial evaluation can be performed to evaluate the outcome of the solution. This is achieved by calculating the reliability importance of each of the seven components of the system for each component. The (5) gives the formula:

$$
I_{Q}(i)=\frac{\partial\left(1-Q_{i}\right)}{\partial Q_{i}}
$$

where this is used to calculate the reliability importance of each component, as shown in (6).

$$
\begin{aligned}
\frac{\partial R_{s}}{\partial R_{1}}= & R_{2} R_{5} R_{7}+R_{3} R_{5} R_{7}+R_{3} R_{6} R_{7}+R_{4} R_{6} R_{7}-R_{2} R_{3} R_{5} R_{7}-R_{3} R_{4} R_{6} R_{7} \\
& -R_{3} R_{5} R_{6} R_{7}-R_{2} R_{4} R_{5} R_{6} R_{7}+R_{2} R_{3} R_{4} R_{5} R_{6} R_{7} \\
\frac{\partial R_{8}}{\partial R_{2}}= & R_{1} R_{5} R_{7}-R_{1} R_{3} R_{5} R_{7}-R_{1} R_{4} R_{5} R_{6} R_{7}+R_{1} R_{3} R_{4} R_{5} R_{6} R_{7} \\
\frac{\partial R_{s}}{\partial R_{3}}= & R_{1} R_{5} R_{7}+R_{1} R_{6} R_{7}-R_{1} R_{2} R_{5} R_{7}-R_{1} R_{4} R_{6} R_{7}-R_{1} R_{5} R_{6} R_{7}+R_{1} R_{2} R_{4} R_{5} R_{6} R_{7} \\
\frac{\partial R_{8}}{\partial R_{4}}= & R_{1} R_{6} R_{7}-R_{1} R_{3} R_{6} R_{7}-R_{1} R_{2} R_{5} R_{6} R_{7}+R_{1} R_{2} R_{3} R_{5} R_{6} R_{7} \\
\frac{\partial R_{8}}{\partial R_{5}}= & R_{1} R_{2} R_{7}+R_{1} R_{3} R_{7}-R_{1} R_{2} R_{3} R_{7}-R_{1} R_{3} R_{6} R_{7}-R_{1} R_{2} R_{4} R_{6} R_{7}+R_{1} R_{2} R_{3} R_{4} R_{6} R_{7} \\
\frac{\partial R_{s}}{\partial R_{6}}= & R_{1} R_{3} R_{7}+R_{1} R_{4} R_{7}-R_{1} R_{3} R_{4} R_{7}-R_{1} R_{3} R_{5} R_{7}-R_{1} R_{2} R_{4} R_{5} R_{7}+R_{1} R_{2} R_{3} R_{4} R_{5} R_{7} \\
\frac{\partial R_{S}}{\partial R_{7}}= & R_{1} R_{2} R_{5}+R_{1} R_{3} R_{5}+R_{1} R_{3} R_{6}+R_{1} R_{4} R_{6}-R_{1} R_{2} R_{3} R_{5}-R_{1} R_{3} R_{4} R_{6} \\
& -R_{1} R_{3} R_{5} R_{6}-R_{1} R_{2} R_{4} R_{5} R_{6}+R_{1} R_{2} R_{3} R_{4} R_{5} R_{6}
\end{aligned}
$$

Figure 4 depict the result of reliability allocation and importance for the ROSS of a spacecraft. Component 1 and Component 7 were among the most important components in the system used for this. Therefore, greater reliability and costs were allocated to these two components. As the failure of the component 1 or component 7 may lead to a complete failure of the system. By calculating the importance of reliability, the results are shown, in Table 1 . Component 5 and component 6 , as in the results obtained using the Jaya algorithm which was added to them with approximately the same reliability, based on the location pf the component in the system. The value of the two composite reliability is also very close by using the importance of reliability equation. The reliability of component 3 was calculated, and the Jaya algorithm allocated a reliability of component 3 less than the two components 5 and the component 6 , as shown in Table 1. Component 2, component 4, and as in the results obtained using Jaya algorithm, they have approximately the same reliability, depending on the location of the component in the system. The significance of the two-component reliability is also closely converged using the significance equation. The results shown in Table 1 that show the importance of each of the vehicles making up the system. The results can be arranged according to the importance of reliability and the position of the component in the system: (i) component 1 , component 7 , (ii) component 5 , component 6 , (iii) component 3 . (iv) component 2 , component 4. The results obtained can be illustrates using the Jaya algorithm shown in Table 1. 


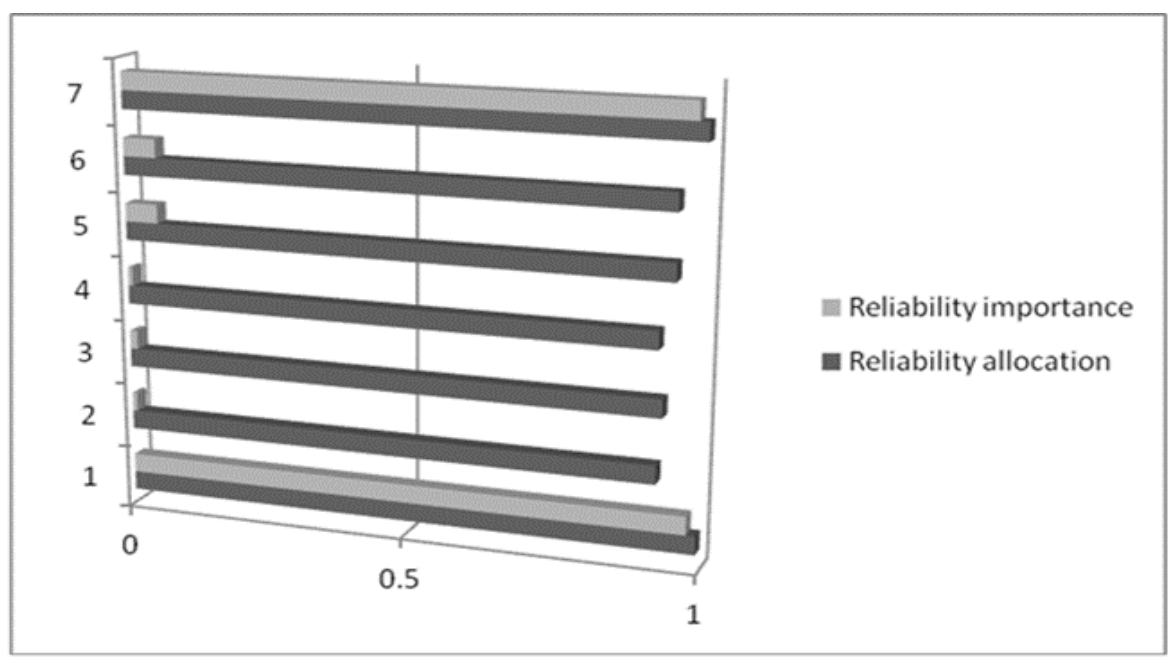

Figure 4. Reliability allocation and importance for the ROSS of a spacecraft

Table 1. Summary Table for optimal reliability allocation of ROSS of spacecraft components

\begin{tabular}{ccc}
\hline Components & Reliability allocation & Reliability importance \\
\hline Component 1 & 0.992 & 0.9762 \\
Component 2 & 0.924 & 0.0086 \\
Component 3 & 0.932 & 0.0129 \\
Component 4 & 0.923 & 0.0084 \\
Component 5 & 0.948 & 0.0582 \\
Component 6 & 0.948 & 0.0582 \\
Component 7 & 0.992 & 0.9762 \\
\hline
\end{tabular}

\section{CONCLUSION}

In this paper, the problem was formulated as a non-linear programming problem. The main objective of this paper is to reduce costs to the lowest possible level while ensuring increased reliability of the system (ROSS). The objective function is the cost function (the logarithmic function), which depends on the unreliability variables, as well as the constraints also depend on the unreliability variables. The problem was solved by using the Jaya algorithm, which proved its effectiveness in finding solutions in the fastest time compared to other algorithms and the accuracy of the solution.

\section{ACKNOWLEDGEMENTS}

The authors thank to AL-Iraqia University, University of Technology, Universiti Malaysia Pahang, Universiti Tun Hussein Onn and Universitas Ahmad Dahlan for supporting this collaborative research in the present work. This work was supported/funded by the Malaysia's Ministry of Higher Education under Fundamental Research Grant Scheme (FRGS/1/2018/ICT01/UTM/02/4).

\section{REFERENCES}

[1] K. K. Aggarwal, Reliability Engineering, Centre for Excellence in Reliability Engineering, vol. 53, no. 9. 1993.

[2] Z. Hassan and M. A. K. Shiker, "Using of generalized baye's theorem to evaluate the reliability of aircraft systems," J. Eng. Appl. Sci., vol. 13, pp. 10797-10801, 2018.

[3] Z. A. H. Hassan and E. K. Mutar, "Evaluation the reliability of a high-pressure oxygen supply system for a spacecraft by using GPD method," Al-Mustansiriyah J. Coll. Educ., vol. 2, pp. 993-1004, 2017.

[4] Z. A. H. Hassan and E. K. Muter, "Geometry of reliability models of electrical system used inside spacecraft," in 2017 Second Al-Sadiq International Conference on Multidisciplinary in IT and Communication Science and Applications (AIC-MITCSA), Dec. 2017, pp. 301-306, doi: 10.1109/AIC-MITCSA.2017.8722980.

[5] Z. A. H. Hassan, C. Udriste, and V. Balan, "Geometric properties of reliability polynomials," UPB Sci. Bull. Ser. A Appl. Math. Phys., vol. 78, no. 1, pp. 3-12, 2016, [Online]. Available: https://www.scientificbulletin.upb.ro/rev_docs_arhiva/full832_872668.pdf

[6] Z. A. H. Hassan and V. Balan, "Fuzzy T-map estimates of complex circuit reliability," in 2017 International Conference on Current Research in Computer Science and Information Technology (ICCIT), Apr. 2017, pp. 136139, doi: 10.1109/CRCSIT.2017.7965548. 
[7] E. K. Mutar and Z. A. H. Hassan, "On the Geometry of the Reliability Polynomials," University of Babylon, 2017.

[8] C. Udriste, I. Tevy, and S. A. Abed, "Problems on multivariate reliability polynomial," Atti della Accad. Peloritana dei Pericolanti-Classe di Sci. Fis. Mat. e Nat., vol. 95, no. 2, pp. A7-1--A7-7, 2017, doi: 10.1478/AAPP.952A7.

[9] N. A. Zainiar, F. Iqbal, A. S. M. Supa'at, and A. W. Yoon Khang, "Robustness metrics for optical networks," Indonesian Journal of Electrical Engineering and Computer Science, vol. 20, no. 2. pp. 845-853, 2020, doi: 10.11591/ijeecs.v20.i2.pp845-853.

[10] S. Abbas Abed, H. Kareem Sulaiman, and Z. Abdul Haddi Hassan, "Reliability Allocation and Optimization for(ROSS) of a Spacecraft by using Genetic Algorithm," in Journal of Physics: Conference Series, Sep. 2019, vol. 1294, no. 3, p. 32034, doi: 10.1088/1742-6596/1294/3/032034

[11] M. H. N. Thi, N. T. P. Loan, T. M. Bui, and T.-V. Vu, "Using SiO2nano-particles for better color uniformity and lumen output in $8500 \mathrm{~K}$ conformal and in-cup white LEDs," Int. J. Electr. Comput. Eng., vol. 11, no. 5, pp. 3897-3902, 2021, doi: 10.11591/ijece.v11i5.pp3897-3902.

[12] M. A. Alawan and O. J. M. Al-Furaiji, "Numerous speeds-loads controller for DC-shunt motor based on PID controller with on-line parameters tuning supported by genetic algorithm," Indones. J. Electr. Eng. Comput. Sci., vol. 21, no. 1, pp. 64-73, 2021, doi: 10.11591/ijeecs.v21.i1.pp64-73.

[13] Y. Maher and B. Danouj, "Survey on deep learning applied to predictive maintenance," Int. J. Electr. Comput. Eng., vol. 10, no. 6, pp. 5592-5598, 2020, doi: 10.11591/ijece.v10i6.pp5592-5598.

[14] C. M. C. Razali, S. S. Abdullah, A. Parnianifard, and A. Faruq, "Adaptive infill sampling strategy for metamodeling: Challenge and future research directions," Bull. Electr. Eng. Informatics, vol. 9, no. 5, pp. 2020 2029, 2020, doi: 10.11591/eei.v9i5.2162.

[15] N. Boopalan, A. K. Ramasamy, and F. H. Nagi, "Faulty antenna detection in a linear array using simulated annealing optimization," Indones. J. Electr. Eng. Comput. Sci., vol. 19, no. 3, pp. 1340-1347, 2020, doi: 10.11591/ijeecs.v19.i3.pp1340-1347.

[16] Iswanto, A. Maarif, B. Kebenaran, and P. Megantoro, "Design of gas concentration measurement and monitoring system for biogas power plant," Indones. J. Electr. Eng. Comput. Sci., vol. 22, no. 2, pp. 118-124, 2020, doi: 10.11591/ijeecs.v22.i2.pp118-124.

[17] K. E. Kaharudin, Z. A. F. M. Napiah, F. Salehuddin, A. S. M. Zain, and A. F. Roslan, "Analysis of analog and RF behaviors in junctionless double gate vertical MOSFET," Bull. Electr. Eng. Informatics, vol. 9, no. 1, pp. 101108, 2020, doi: 10.11591/eei.v9i1.1861.

[18] T. A. Khan, M. M. Alam, M. J. Tahir, K. Kadir, Z. Shahid, and M. S. Mazliham, "Optimized health parameters using PSO: A cost effective RFID based wearable gadget with less false alarm rate," Indones. J. Electr. Eng. Comput. Sci., vol. 15, no. 1, pp. 230-239, 2019, doi: 10.11591/ijeecs.v15.i1.pp230-239.

[19] L. V Nguyen, N. V Bach, H. T. Do, and M. T. Nguyen, "Combined ILC and PI regulator for wastewater treatment plants," Telkomnika (Telecommunication Comput. Electron. Control., vol. 18, no. 2, pp. 1054-1061, 2020, doi: 10.12928/TELKOMNIKA.V18I2.14895.

[20] S. A. Abed, C. Udriste, and I. Tevy, "Optimal reliability allocation for redundancy series-parallel systems," Eur. J. Pure Appl. Math., vol. 10, no. 4, pp. 877-889, 2017.

[21] L. Zhang, N. Zhang, F. Zhao, and Y. Chen, "A genetic-algorithm-based experimental technique for determining heat transfer coefficient of exterior wall surface,” Appl. Therm. Eng., vol. 24, no. 2-3, pp. 339-349, Feb. 2004, doi: 10.1016/j.applthermaleng.2003.07.005.

[22] W. Kuo and V. R. Prasad, "An annotated overview of system-reliability optimization," IEEE Trans. Reliab., vol. 49, no. 2, pp. 176-187, Jun. 2000, doi: 10.1109/24.877336.

[23] P. Lakey and A. Neufelder, "System and software reliability assurance notebook," Rome Lab., 1997, [Online]. Available: https://www.cs.colostate.edu/ cs530/rh/secs1-3.pdf.

[24] K. Dohmen, "Inclusion-Exclusion and Network Reliability,” Electron. J. Comb., vol. 5, no. 1, pp. R36-R36, Jun. 1998, doi: 10.37236/1374.

[25] C. Udriste, S. A. Abed, and I. Tevy, "Geometric programming approaches of reliability allocation," UPB Sci. Bull, vol. 79, no. 3, pp. 3-10, 2017.

[26] A. Mettas, "Reliability allocation and optimization for complex systems," in Annual Reliability and Maintainability Symposium. 2000 Proceedings. International Symposium on Product Quality and Integrity (Cat. No.00CH37055), 2000, pp. 216-221, doi: 10.1109/RAMS.2000.816310.

[27] M. K. Khamees, M. A. Ismail, U. Yunan, and S. Kasim, "Review on Intrusion Detection System Based on The Goal of The Detection System," Int. J. Integr. Eng., vol. 10, no. 6, Nov. 2018, doi: 10.30880/ijie.2018.10.06.028.

[28] M. Aljanabi, M. A. Ismail, and A. H. Ali, "Intrusion Detection Systems, Issues, Challenges, and Needs," Int. J. Comput. Intell. Syst., vol. 14, no. 1, p. 560, 2021, doi: 10.2991/ijcis.d.210105.001.

[29] M. Aljanabi, M. A. Ismail, and V. Mezhuyev, "Improved TLBO-JAYA Algorithm for Subset Feature Selection and Parameter Optimisation in Intrusion Detection System," Complexity, vol. 2020, pp. 1-18, May 2020, doi: $10.1155 / 2020 / 5287684$.

[30] L. K. Shaakir, E. S. Abdulwahid, and A. A. Hijab, “(An)-Potent Operators on Hilbert Space," Iraqi J. Comput. Sci. Math., vol. 1, no. 1, pp. 13-17, 2020.

[31] M. S. Fiadh and W. H. Hanoon, "2-Visible Submodules and Fully 2-Visible Modules," Iraqi J. Comput. Sci. Math., vol. 1, no. 2, pp. 24-28, Jul. 2020, doi: 10.52866/ijcsm.2020.01.02.004 
[32] M. Al-Janabi and M. A. Ismail, "Improved Intrusion Detection Algorithm based on TLBO and GA Algorithms," Int. Arab J. Inf. Technol., vol. 18, no. 2, pp. 170-179, 2021, doi: 10.34028/iajit/18/2/5.

[33] M. Aljanabi et al., "Large Dataset Classification Using Parallel Processing Concept," JOIV Int. J. Informatics Vis., vol. 4, no. 4, p. 191, Dec. 2020, doi: 10.30630/joiv.4.4.361.

[34] D. S. Wais and W. S. Majeed, "The gravitational search algorithm for incorporating TCSC devices into the system for optimum power flow," Int. J. Electr. Comput. Eng., vol. 11, no. 6, pp. 4678-4688, 2021, doi: 10.11591/ijece.v11i6.pp4678-4688.

[35] R. A. I. Alhayali, M. Aljanabi, A. H. Ali, M. A. Mohammed, and T. Sutikno, "Optimized machine learning algorithm for intrusion detection,” Indones. J. Electr. Eng. Comput. Sci., vol. 24, no. 1, pp. 590-599, 2021, doi: 10.11591/ijeecs.v24.i1.pp590-599.

[36] E. A. Lisangan and S. C. Sumarta, "An improved fuzzy ant colony system for route selection based on real time traffic condition,” IAES Int. J. Artif. Intell., vol. 10, no. 1, pp. 51-59, 2021, doi: 10.11591/ijai.v10.i1.pp51-59.

[37] N. A. M. Said, W. A. A. Saleh, and W. A. Halim, "Voltage harmonics reduction in single phase 9-level transistor clamped H-bridge inverter using nearest level control method," Indones. J. Electr. Eng. Comput. Sci., vol. 20, no. 3, pp. 1725-1732, 2020, doi: 10.11591/IJEECS.V20.I3.PP1725-1732.

[38] M. Regad, M. Helaimi, R. Taleb, A. M. Othman, and H. A. Gabbar, "Control of hybrid power system based renewable energy generations using pid controller," Int. J. Power Electron. Drive Syst., vol. 11, no. 4, pp. 17751784, 2020, doi: 10.11591/ijpeds.v11.i4.pp1775-1784.

[39] H. K. Tran, P. D. Lam, T. T. Trang, X. T. Nguyen, and H.-N. Nguyen, "Fuzzy gain scheduling control apply to an RC Hovercraft," Int. J. Electr. Comput. Eng., vol. 10, no. 3, pp. 2434-2440, 2020, doi: 10.11591/ijece.v10i3.pp2434-2440.

[40] Widjonarko, C. Avian, A. Setiawan, M. Rusli, and E. Iskandar, "Capacitor bank controller using artificial neural network with closed-loop system,” Bull. Electr. Eng. Informatics, vol. 9, no. 4, pp. 1379-1386, 2020, doi: 10.11591/eei.v9i4.2411.

[41] M. Z. M. Tumari, M. M. Zahar, and M. A. Ahmad, "Optimal tuning of a wind plant energy production based on improved grey wolf optimizer," Bull. Electr. Eng. Informatics, vol. 10, no. 1, pp. 23-30, 2020, doi: 10.11591/eei.v10i1.2509.

[42] S. Jamian et al., "Review on controller design in pneumatic actuator drive system," Telkomnika (Telecommunication Comput. Electron. Control., vol. 18, no. 1, pp. 332-342, 2020, doi: 10.12928/TELKOMNIKA.V18I1.12626.

[43] H. R. Ibraheem, Z. F. Hussain, S. M. Ali, M. Aljanabi, M. A. Mohammed, and T. Sutikno, "A new model for large dataset dimensionality reduction based on TLBO and LR," Telkomnika (Telecommunication Comput. Electron. Control., vol. 18, no. 3, pp. 1688-1694, 2020, doi: 10.12928/TELKOMNIKA.v18i3.13764.

[44] T. M. Phan, P. T. Ha, T. L. Duong, and T. T. Nguyen, "Improved particle swarm optimization algorithms for economic load dispatch considering electric market," Int. J. Electr. Comput. Eng., vol. 10, no. 4, pp. 3918-3926, 2020, doi: 10.11591/ijece.v10i4.pp3918-3926.

[45] N. A. Ali, A. R. Syafeeza, A. S. Jaafar, and M. K. M. F. Alif, "Autism spectrum disorder classification on electroencephalogram signal using deep learning algorithm,” IAES Int. J. Artif. Intell., vol. 9, no. 1, pp. 91-99, 2020, doi: 10.11591/ijai.v9.i1.pp91-99.

[46] S. Nayak, S. K. Kar, and S. S. Dash, "Combined fuzzy PID regulator for frequency regulation of smart grid and conventional power systems," Indones. J. Electr. Eng. Comput. Sci., vol. 24, no. 1, pp. 12-21, 2021, doi: 10.11591/ijeecs.v24.i1.pp12-21.

[47] M. Z. Mohd Tumari, M. H. Suid, and M. A. Ahmad, "A modified grey wolf optimizer for improving wind plant energy production," Indones. J. Electr. Eng. Comput. Sci., vol. 18, no. 3, pp. 1123-1129, 2020, doi: 10.11591/ijeecs.v18.i3.pp1123-1129.

[48] R. A. Ibrahem Alhayali, M. A. Ahmed, Y. M. Mohialden, and A. H. Ali, "Efficient method for breast cancer classification based on ensemble hoffeding tree and naïve Bayes," Indones. J. Electr. Eng. Comput. Sci., vol. 18, no. 2, pp. 1074-1080, 2020, doi: 10.11591/ijeecs.v18.i2.pp1074-1080.

[49] S. S. Sadiq, A. M. Abdulazeez, and H. Haron, "Solving multi-objective master production schedule problem using memetic algorithm," Indones. J. Electr. Eng. Comput. Sci., vol. 18, no. 2, pp. 938-945, 2020, doi: 10.11591/ijeecs.v18.i2.pp938-945.

[50] S. M. Hossain and A. H. Chowdhury, "Multi-objective optimal placement of distributed generations for dynamic loads," Int. J. Electr. Comput. Eng., vol. 9, no. 4, pp. 2303-2313, 2019, doi: 10.11591/ijece.v9i4.pp2303-2313.

[51] T. D. Apale and A. B. Patil, "Optimization study of fuzzy parametric uncertain system," IAES Int. J. Artif. Intell., vol. 8, no. 1, pp. 14-25, 2019, doi: 10.11591/ijai.v8.i1.pp14-25.

[52] R. A. Hamzah, M. G. Y. Wei, and N. S. N. Anwar, "Stereo matching based on absolute differences for multiple objects detection," Telkomnika (Telecommunication Comput. Electron. Control., vol. 17, no. 1, pp. 261-267, 2019, doi: 10.12928/TELKOMNIKA.v17i1.9185.

[53] T. A. A. Almuhsen and A. J. Sultan, "Coordination of directional overcurrent and distance relays based on nonlinear multivariable optimization,” Indones. J. Electr. Eng. Comput. Sci., vol. 17, no. 3, pp. 1194-1205, 2019 , doi: 10.11591/ijeecs.v17.i3.pp1194-1205.

[54] R. H. Salimin et al., "Multi cases optimal reactive power dispatch using evolutionary programming," Indones. J. Electr. Eng. Comput. Sci., vol. 17, no. 2, pp. 662-670, 2019, doi: 10.11591/ijeecs.v17.i2.pp662-670.

[55] K. A. F. A. Samah et al., "Optimization of house purchase recommendation system (HPRS) using genetic algorithm," Indones. J. Electr. Eng. Comput. Sci., vol. 16, no. 3, pp. 1530-1538, 2019, doi: 10.11591/ijeecs.v16.i3.pp1530-1538. 
[56] Y. Dasril, Z. Zakaria, and I. B. Mohd, "Using alpha-cuts and constraint exploration approach on quadratic programming problem," Telkomnika (Telecommunication Comput. Electron. Control., vol. 16, no. 6, pp. 27822790, 2018, doi: 10.12928/TELKOMNIKA.v16i6.11584.

[57] M. S. Jamri, M. N. Kamarudin, and M. L. M. Jamil, "Total power deficiency estimation of isolated power system network using full-state observer method," Indones. J. Electr. Eng. Comput. Sci., vol. 23, no. 3, pp. 1249-1257, 2021, doi: 10.11591/ijeecs.v23.i3.pp1249-1257.

[58] W. N. W. Md Adnan, N. Y. Dahlan, and I. Musirin, "Modeling baseline energy using artificial neural network: A small dataset approach," Indones. J. Electr. Eng. Comput. Sci., vol. 12, no. 2, pp. 662-669, 2018, doi: 10.11591/ijeecs.v12.i2.pp662-669.

[59] N. T. Thang, N. D. Phuong, P. V Thanh, and C. T. Hien, "An effectively modified firefly algorithm for economic load dispatch problem," Telkomnika (Telecommunication Comput. Electron. Control., vol. 16, no. 5, pp. 24332436, 2018, doi: 10.12928/TELKOMNIKA.v16i5.10545.

[60] N. A. M. Kamari, I. Musirin, Z. A. Hamid, and M. H. M. Zaman, "Oscillatory stability prediction using pso based synchronizing and damping torque coefficients,” Bull. Electr. Eng. Informatics, vol. 7, no. 3, pp. 331-344, 2018, doi: 10.11591/eei.v7i3.961.

[61] T. N. S. Tengku Zawawi, A. R. Abdullah, M. H. Jopri, T. Sutikno, N. M. Saad, and R. Sudirman, “A review of electromyography signal analysis techniques for musculoskeletal disorders," Indones. J. Electr. Eng. Comput. Sci., vol. 11, no. 3, pp. 1136-1146, 2018, doi: 10.11591/ijeecs.v11.i3.pp1136-1146.

[62] N. N. S. Abdul Rahman, N. M. Saad, A. R. Abdullah, M. R. M. Hassan, M. S. S. M. Basir, and N. S. M. Noor, "Automated real-time vision quality inspection monitoring system," Indones. J. Electr. Eng. Comput. Sci., vol. 11, no. 2, pp. 775-783, 2018, doi: 10.11591/ijeecs.v11.i2.pp775-783.

[63] M. Z. K. Hawari and N. I. A. Apandi, "Industry 4.0 with intelligent manufacturing 5G mobile robot based on genetic algorithm," Indones. J. Electr. Eng. Comput. Sci., vol. 23, no. 3, pp. 1376-1384, 2021, doi: 10.11591/ijeecs.v23.i3.pp1376-1384.

[64] M. N. Kamarudin, S. M. Rozali, and M. S. Jamri, “Active cooling photovoltaic with iot facility," Int. J. Power Electron. Drive Syst., vol. 12, no. 3, pp. 1494-1504, 2021, doi: 10.11591/ijpeds.v12.i3.pp1494-1504.

[65] M. R. Jubair Al-Hiealy, M. S. B. Abdul Majed Shikh, A. B. Jalil, S. A. Rahman, and M. Jarrah, "Management switching angles real-time prediction by artificial neural network," Indones. J. Electr. Eng. Comput. Sci., vol. 23, no. 1, pp. 110-119, 2021, doi: 10.11591/ijeecs.v23.i1.pp110-119.

[66] Al-Khowarizmi, R. Syah, M. K. M. Nasution, and M. Elveny, "Sensitivity of MAPE using detection rate for big data forecasting crude palm oil on k-nearest neighbor," Int. J. Electr. Comput. Eng., vol. 11, no. 3, pp. 26962703, 2021, doi: 10.11591/ijece.v11i3.pp2696-2703.

[67] A. Z. Foeady, S. R. Riqmawatin, and D. C. R. Novitasari, "Lung cancer classification based on CT scan image by applying FCM segmentation and neural network technique," Telkomnika (Telecommunication Comput. Electron. Control., vol. 19, no. 4, pp. 1284-1290, 2021, doi: 10.12928/TELKOMNIKA.v19i4.18874.

[68] V. Srisarkun and C. Jittawiriyanukoon, "Evaluation of weighted fusion for scalar images in multi-sensor network," Bull. Electr. Eng. Informatics, vol. 10, no. 2, pp. 911-916, 2021, doi: 10.11591/eei.v10i2.1792.

[69] S. K. G. Singh, R. Hassan, and M. Aljanabi, "Incorporation Local Protein Structure Information With Clustering Based Algorithm To Predict Structural Classes,” Acad. Fundam. Comput. Res., vol. 1, no. 1, pp. 41-55, 2020.

[70] W. N. Wan Md Adnan, N. Yenita Dahlan, I. Musirin, W. N. W. Md Adnan, N. Y. Dahlan, and I. Musirin, "Development of option c measurement and verification model using hybrid artificial neural network-cross validation technique to quantify saving," IAES International Journal of Artificial Intelligence (IJ-AI), vol. 9, no. 1. p. 25, Mar. 2020, doi: 10.11591/ijai.v9.i1.pp25-32.

[71] J. R. and N. G. Cholli, "An efficient approach for secured communication in wireless sensor networks," International Journal of Electrical and Computer Engineering (IJECE), vol. 10, no. 2. p. 1641, Apr. 2020, doi: 10.11591/ijece.v10i2.pp1641-1647.

[72] B. Prathiba, K. Jaya Sankar, and V. Sumalatha, "Novel framework of retaining maximum data quality and energy efficiency in reconfigurable wireless sensor network," International Journal of Electrical and Computer Engineering, vol. 9, no. 4. pp. 2893-2901, 2019, doi: 10.11591/ijece.v9i4.pp2983-2901.

[73] B. Qas Elias, M. Alsajri, P. J. Soh, and A. A. Al-hadi, "Design of Flexible Planar Antennas Using Substrate Gap Structure for Surface Wave Reduction," in 2019 22nd International Conference on Control Systems and Computer Science (CSCS), May 2019, pp. 453-458, doi: 10.1109/CSCS.2019.00083.

[74] M. Alsajri, M. A. Ismail, and S. Abdul-Baqi, "A Review on the Recent Application of Jaya Optimization Algorithm," in 2018 1st Annual International Conference on Information and Sciences (AiCIS), Nov. 2018, pp. 129-132, doi: 10.1109/AiCIS.2018.00034.

[75] A. H. Ali, M. Aljanabi, and M. A. Ahmed, "Fuzzy generalized Hebbian algorithm for large-scale intrusion detection system," Int. J. Integr. Eng., vol. 12, no. 1, pp. 81-90, 2020.

[76] M. A. Bahari, Z. A. Baharudin, T. Sutikno, A. I. A. Rahman, M. A. M. Hanafiah, and M. Ibrahim, "An analysis of manual and autoanalysis for submicrosecond parameters in the typical first lightning return stroke," Indonesian Journal of Electrical Engineering and Computer Science, vol. 23, no. 3. pp. 1451-1457, 2021, doi: 10.11591/ijeecs.v23.i3.pp1451-1457.

[77] V. H. Ahgajan, Y. G. Rashid, and F. M. Tuaimah, "Artificial bee colony algorithm applied to optimal power flow solution incorporating stochastic wind power," International Journal of Power Electronics and Drive Systems, vol. 12, no. 3. pp. 1890-1899, 2021, doi: 10.11591/ijpeds.v12.i3.pp1890-1899. 
[78] T. T. Nguyen, N. T. Nguyen, and T. D. Nguyen, "Optimal electric distribution network configuration using adaptive sunflower optimization,” Bulletin of Electrical Engineering and Informatics, vol. 10, no. 4. pp. 17771784, 2021, doi: 10.11591/EEI.V10I4.2588.

[79] O. P. G. Prakash, A. Jaya, S. Ananthakumaran, and G. Ganesh, "Predicting the user navigation pattern from web logs using weighted support approach," Indonesian Journal of Electrical Engineering and Computer Science, vol. 21, no. 3. pp. 1722-1730, 2021, doi: 10.11591/ijeecs.v21.i3.pp1722-1730.

[80] T. L. Duong, L. H. Pham, T. T. T. T. Nguyen, and T. T. T. T. Nguyen, "Application of a new constraint handling method for economic dispatch considering electric market," Bulletin of Electrical Engineering and Informatics, vol. 9, no. 4. pp. 1542-1549, Aug. 2020, doi: 10.11591/eei.v9i4.2351.

[81] G. Furano et al., "Towards the Use of Artificial Intelligence on the Edge in Space Systems: Challenges and Opportunities," IEEE Aerosp. Electron. Syst. Mag, vol. 35, no. 12, pp. 44-56, Dec. 2020, doi: 10.1109/MAES.2020.3008468.

[82] S. Sokolov, A. Zhilenkov, S. Chernyi, A. Nyrkov, and N. Glebov, "Hybrid neural networks in cyber physical system interface control systems," Bull. Electr. Eng. Informatics, vol. 9, no. 3, pp. 1268-1275, 2020, doi: 10.11591/eei.v9i3.1293.

[83] B. Nethravathi and V. N. Kamalesh, "Fault isolation technique for decentralized survivable communication network systems via regions and paths," Indones. J. Electr. Eng. Comput. Sci., vol. 17, no. 1, pp. 533-542, 2020 , doi: 10.11591/IJEECS.V17.I1.PP533-542.

[84] S. Krishnamurthy, R. Kannan, C. C. Kiong, T. B. Ibrahim, and Y. Abdullah, "Impact of gamma-ray irradiation on dynamic characteristics of $\mathrm{Si}$ and $\mathrm{SiC}$ power MOSFETs," Int. J. Electr. Comput. Eng., vol. 9, no. 2, pp. 14531460, 2019, doi: 10.11591/ijece.v9i2.pp1453-1460. 